\title{
NOMES PRÓPRIOS EM DOM CASMURRO: OPÇÕES DE TRADUÇÃO EM INGLÊS E FRANCÊS
}

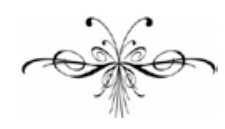

\section{CynthiA BEATRICE CostA}

\begin{abstract}
Resumo: A proposta do presente trabalho é analisar as traduções de nomes próprios e formas de tratamento nas traduções mais recentes em inglês e francês do romance Dom Casmurro, de Machado de Assis. Com base na noção de "tradução etnocêntrica”, de Antoine Berman, pretende-se observar a presença da cultura traduzida no texto, em oposição à predominância etnocêntrica.
\end{abstract}

Palavras-chave: Tradução; Nomes próprios; Dom Casmurro; Machado de Assis.

\begin{abstract}
The present work aims at analyzing the translation of proper nouns and titles in the most recent translations of the novel Dom Casmurro, by Machado de Assis, into English and French. Basing on the notion of "ethnocentric translation", by Antoine Berman, the intention is to observe the presence of the translated culture in the text, as opposed to the ethnocentric predominance.
\end{abstract}

Keywords: Translation; Proper Nouns; Dom Casmurro; Machado de Assis.

$\mathrm{E}$ ntre os tantos desafios enfrentados pelo tradutor, um parece ser particularmente controverso: a tradução (ou não tradução) de nomes próprios. Na história ocidental, houve uma longa tradição, iniciada com os primeiros textos traduzidos de que se tem conhecimento - menos adotada atualmente - de se traduzir nomes de pessoas e lugares, sobretudo nos campos da história da religião, o que resultou em figuras relevantes conhecidas por múltiplas alcunhas. Exemplos disso são São Tiago (Saint James em inglês e Saint-Jacques em francês), Carlos Magno (Charlemagne para falantes de francês e inglês, Carolus Magus em latim e Karl, der Grosse em alemão) e o aportuguesado Martinho Lutero (Martin Luther em alemão).

Essa prática mostra que a cultura tradutora tendia (e, por vezes, ainda tende) a apagar traços da cultura traduzida, como que adaptando o texto à sua realidade e facilitando-o para o seu leitor. A tradução etnocêntrica, isto é, que procura remodelar a cultura estrangeira ao seu modo, "é uma realidade histórica", como ressalta Antoine Berman (2012, p. 41). 
Na literatura estrangeira traduzida no Brasil, prova-se que não foram apenas países considerados dominantes que seguiram a linha "etnocêntrica" em suas traduções. Há também exemplos conhecidos de nomes próprios traduzidos aqui, e que assim se consolidaram no imaginário popular, como os irmãos do conto "João e Maria” ("Hänsel und Gretel”, no alemão dos Irmãos Grimm; é interessante saber que os nomes originais foram mantidos em Portugal e modificados no Brasil), Romeu e Julieta (do inglês Romeo and Juliet, de Shakespeare) e o Fausto (Faust, da lenda alemã e da obra de Goethe).

Para o tradutor estrangeiro, o romance Dom Casmurro, de Machado de Assis, impõe dois dilemas já no título. Tanto no que diz respeito ao nome próprio, como à forma de tratamento. Reforça o tradutor John Gledson: "Os problemas do tradutor começam no título intraduzível” (GLEDSON, 2006, p. 283). Publicada em 1899, essa que em geral é considerada por críticos literários e professores de literatura brasileiros uma das obras-primas do autor foi traduzida, segundo a Academia Brasileira de Letras, para pelo menos 10 línguas estrangeiras, entre as quais inglês, francês, alemão, italiano e espanhol.

Neste artigo, o interesse se concentra nas traduções mais recentes feitas para o inglês e o francês, cujas primeiras edições foram publicadas, respectivamente, em 1997 e 1983. A versão de 1997 é do inglês John Gledson, crítico literário especializado em literatura de língua portuguesa, sobretudo em Machado de Assis. A de 1983, reeditada em formato pocket em 2002 pelas Éditions Métailié (e é esta edição utilizada aqui) teve autoria de Anne-Marie Quint, professora de língua e literatura portuguesas na universidade Paris-Sorbonne e tradutora também de Camões, entre outros autores. Além deles, outros dois tradutores foram responsáveis em versões em inglês - a americana Helen Caldwell, em 1953, e o escocês Robert ScottBuccleuch, em 1994 - e um em francês, Francis de Miomandre, em 1936.

Para o cotejo, foi escolhida a nova edição de Dom Casmurro (2012) da Editora Ática, por ser também a mais recente publicada no Brasil e cotejada com a edição crítica do Instituto Nacional do Livro.

Tomando por base essas duas versões e o original editado pela Ática, a de John Gledson e de Anne-Marie Quint, o presente texto objetiva analisar a questão da tradução dos nomes próprios, procurando compreender, com base nas noções de “tradução etnocêntrica” (BERMAN, 2012) e de "estrangeirização" (VENUTI, 2002), de que maneira os tradutores permitiram a entrada e até mesmo o destaque de outra cultura em seu texto.

\section{Nomes de lugares}

Dom Casmurro se passa no Rio de Janeiro do final do século XIX, e a antiga capital brasileira desempenha um importante papel de fundo na narrativa. Há referências frequentes a bairros e ruas da cidade, aos arredores e a logradouros mais distantes do estado do Rio de Janeiro, além de outras tantas aos estados brasileiros de Minas Gerais, São Paulo e Rio Grande do Sul.

No quadro a seguir, são comparadas a forma original e as versões em inglês, de John Gledson, e em francês, de Anne-Marie Quint, das principais referências a lugares do texto. 


\begin{tabular}{|c|c|c|}
\hline NOME DO LUGAR & $\begin{array}{c}\text { QUINT } \\
1983 \text { - edição de } 2002\end{array}$ & $\begin{array}{c}\text { GLEDSON } \\
1997\end{array}$ \\
\hline Engenho Novo (p. 19) & Engenho Novo (p. 7) & $\begin{array}{l}\text { Engenho Novo (p. 3) } \\
\text { [acompanhado da primeira } \\
\text { nota de rodapé do livro: “A } \\
\text { recently developed suburb of } \\
\text { Rio de Janeiro”.] }\end{array}$ \\
\hline Central (p. 19) & Gare Centrale (p. 7) & Central line train (p. 3) \\
\hline Petrópolis (p. 19) & Pétropolis (p. 7) & $\begin{array}{l}\text { Petrópolis (p. 3) } \\
\text { [acompanhado da longa } \\
\text { segunda nota de rodapé: } \\
\text { "Petrópolis is a city about } \\
\text { twenty miles from Rio de } \\
\text { Janeiro, situated in the } \\
\text { mountains overlooking } \\
\text { Guanabara Bay (...) From the } \\
\text { mid-century on, Pedro II } \\
\text { encouraged German } \\
\text { immigration to the city - thus } \\
\text { the names of such areas as } \\
\text { Renânia (literally, } \\
\text { Rhineland)”.] }\end{array}$ \\
\hline Renânia (p. 19) & Renania (p. 8) & Renânia (p. 4) \\
\hline $\begin{array}{l}\text { Rua de Matacavalos (p. } \\
\text { 20) }\end{array}$ & rue de Matacavalos (p. 9) & $\begin{array}{l}\text { Rua de Matacavalos (p. 5) } \\
\text { [acompanhado da nota de } \\
\text { rodapé: "Now the Rua do } \\
\text { Riachuelo in the center of Rio } \\
\text { de Janeiro, it was then on the } \\
\text { outskirts of the center, } \\
\text { separate from the main } \\
\text { commercial area".] }\end{array}$ \\
\hline $\begin{array}{l}\text { antiga fazenda de Itaguaí } \\
\text { (p. 25) }\end{array}$ & $\begin{array}{l}\text { ancien domaine d'Itaguaï } \\
\text { (p. 16) }\end{array}$ & $\begin{array}{l}\text { old plantation at Itaguaí (p. } \\
\text { 11) } \\
\text { [acompanhado da nota de } \\
\text { rodapé: “A town about forty } \\
\text { miles west of Rio de Janeiro, } \\
\text { on the low-lying land near the } \\
\text { ocean. Bento's father would } \\
\text { have been a sugar planter”.] }\end{array}$ \\
\hline Rio de Janeiro (p. 25) & Rio de Janeiro (p. 16/17) & Rio de Janeiro (p. 11) \\
\hline rua das Violas (p. 26) & rue des Violas (p. 19) & Rua das Violas (p. 13) \\
\hline Corcovado (p. 35) & Corcovado (p. 32) & $\begin{array}{l}\text { Corcovado (p. 24) } \\
\text { [acompanhado da nota de } \\
\text { rodapé: "The high mountain to } \\
\text { the south of the center of Rio } \\
\text { de Janeiro, on which the } \\
\text { famous statue of Christ the } \\
\text { Redeemer now stands".] }\end{array}$ \\
\hline
\end{tabular}




\begin{tabular}{|c|c|c|}
\hline fortaleza da Laje (p. 46) & $\begin{array}{l}\text { fortresse de Laje (p. 50) } \\
\text { [acompanhado da } \\
\text { primeira nota de rodapé } \\
\text { do livro: "Ilot situé au } \\
\text { milieu de la barre de } \\
\text { Guanabara, à l'entrée de } \\
\text { la baie de Rio de } \\
\text { Janeiro.”] }\end{array}$ & $\begin{array}{l}\text { Laje fortress (p. 38) } \\
\text { [acompanhado da nota de } \\
\text { rodapé: “On a small island in } \\
\text { the mouth of the bay on which } \\
\text { Rio de Janeiro stands.”] }\end{array}$ \\
\hline Bordéus (p. 46) & Bordeaux (p. 46) & Bordeaux (p. 38) \\
\hline Santa Teresa (p. 48) & Santa Teresa (p. 48) & Santa Teresa (p. 41) \\
\hline ladeira da Glória (p. 49) & $\begin{array}{l}\text { raidillon de la Gloria (p. } \\
54 \text { ) }\end{array}$ & $\begin{array}{l}\text { Glória Church (p. 42) } \\
\text { [acompanhado da nota de } \\
\text { rodapé: “A small baroque } \\
\text { church, situated at the top of a } \\
\text { hill, and a well-known } \\
\text { landmark not more than a mile } \\
\text { of two from Bento's house.”] }\end{array}$ \\
\hline Passeio Público (p. 53) & Jardin Public (p. 61) & $\begin{array}{l}\text { Promenade (p. 46) } \\
\text { [acompanhado da nota de } \\
\text { rodapé: “The Passeio Público, } \\
\text { part of which still exists, was } \\
\text { a formal garden on the edge of } \\
\text { the water, commanding an } \\
\text { extensive view of the } \\
\text { Guanabara Bay.”] }\end{array}$ \\
\hline S. Paulo (p. 59) & São Paulo (p. 73) & São Paulo (p. 55) \\
\hline $\begin{array}{l}\text { o quartel dos Barbonos e } \\
\text { a Casa da Correção (p. } \\
\text { 81) }\end{array}$ & $\begin{array}{l}\text { la caserne des Barbonos } \\
\text { [acompanhado da nota } \\
\text { de rodapé: “Caserne de } \\
\text { la Police Militaire, située } \\
\text { rue des Barbonos".] et } \\
\text { Maison de Correction. } \\
\text { (p. 110/111) }\end{array}$ & $\begin{array}{l}\text { the Barbonos barracks, and } \\
\text { the reformatory (p. 84) }\end{array}$ \\
\hline $\begin{array}{l}\text { Carmo ou S. Francisco } \\
\text { Candelária } \\
\text { (p. 83) }\end{array}$ & $\begin{array}{l}\text { Carmo ou à } \quad \text { São } \\
\text { Francisco } \\
\text { Candelaria } \\
\text { (p. 114) }\end{array}$ & $\begin{array}{l}\text { Carmo or São Francisco } \\
\text { Candelária } \\
\text { (p. 87) }\end{array}$ \\
\hline Rua do Ouvidor (p. 99) & rue de l’Ouvidor (p. 144) & $\begin{array}{l}\text { Rua do Ouvidor (p. 109) } \\
\text { [acompanhado da nota de } \\
\text { rodapé: “The Rua do Ouvidor } \\
\text { was the central shopping street } \\
\text { of downtown Rio de Janeiro; } \\
\text { most of the fashion shops } \\
\text { were French”.] }\end{array}$ \\
\hline $\begin{array}{l}\text { Rua da Quitanda (p. } \\
\text { 116) }\end{array}$ & $\begin{array}{l}\text { rue de la Quitanda (p. } \\
\text { 176) }\end{array}$ & $\begin{array}{l}\text { Rua da Quitanda (p. 131) } \\
\text { [acompanhado da nota de } \\
\text { rodapé: “A street in the central } \\
\text { business quarter of Rio de }\end{array}$ \\
\hline
\end{tabular}




\begin{tabular}{|c|c|c|}
\hline & & Janeiro.”] \\
\hline $\begin{array}{l}\text { Campo da Aclamação } \\
\text { (p. 120) }\end{array}$ & $\begin{array}{l}\text { place de l'Acclamation } \\
\text { (p. 182) }\end{array}$ & $\begin{array}{l}\text { Campo da Aclamação (p. 136) } \\
\text { [acompanhado da nota de } \\
\text { rodapé: "The Campo da } \\
\text { Aclamação was a large open } \\
\text { área near the center of Rio de } \\
\text { Janeiro, now occupied by the } \\
\text { Praça da República.] }\end{array}$ \\
\hline $\begin{array}{l}\text { Rua dos Inválidos (p. } \\
\text { 128) }\end{array}$ & rue des Invalides (p. 196) & Rua dos Inválidos (p. 146) \\
\hline Tijuca (p. 153) & Tijuca (p. 244) & Tijuca (p. 180) \\
\hline Andaraí (p. 153) & Andaraï (p. 245) & $\begin{array}{l}\text { Andaraí (p. 181) } \\
\text { [acompanhado da nota de } \\
\text { rodapé: "Andaraí was a } \\
\text { middle-class suburb in the } \\
\text { foothills".] }\end{array}$ \\
\hline $\begin{array}{l}\text { praia do Flamengo (p. } \\
163)\end{array}$ & $\begin{array}{l}\text { plage de Flamengo (p. } \\
\text { 262) }\end{array}$ & Flamengo beach (p. 194) \\
\hline Flamengo (p. 170) & Flamengo (p. 276) & $\begin{array}{l}\text { Flamengo (p. 203) } \\
\text { [acompanhado da nota de } \\
\text { rodapé: Flamengo is an área } \\
\text { of Rio de Janeiro further from } \\
\text { the center, and just beyond } \\
\text { Gloria, on Guanabara Bay. } \\
\text { Escobar has moved up in the } \\
\text { world.”] }\end{array}$ \\
\hline Rua da Princesa (p. 170) & $\begin{array}{l}\text { rue de la Princesse (p. } \\
\text { 276) }\end{array}$ & Rua da Princesa (p. 203) \\
\hline $\begin{array}{l}\text { o pedaço de praia entre a } \\
\text { Glória e o Flamengo (p. } \\
170)\end{array}$ & $\begin{array}{l}\text { la partie de plage } \\
\text { comprise entre Gloria et } \\
\text { Flamengo (p. 276) }\end{array}$ & $\begin{array}{l}\text { the stretch of beach between } \\
\text { Glória and Flamengo (p. 203) }\end{array}$ \\
\hline Lapa (p. 174) & Lapa (p. 283) & Lapa (p. 208) \\
\hline $\begin{array}{l}\text { Europa, } \\
\text { Petrópolis } \\
\text { (p. 182) }\end{array}$ & $\begin{array}{l}\text { l’Europe, le Minas } \\
\text { Gerais, Petropolis (p. } \\
\text { 298) }\end{array}$ & $\begin{array}{l}\text { Europe, Minas, Petrópolis } \\
\text { (p. 219) }\end{array}$ \\
\hline $\begin{array}{l}\text { Largo da Lapa } \\
\text { (p. 184) }\end{array}$ & place de Lapa (p. 303) & Largo da Lapa (p. 223) \\
\hline $\begin{array}{l}\text { mar da Glória, nem a } \\
\text { serra dos Órgãos, nem a } \\
\text { fortaleza de Santa Cruz e } \\
\text { as outras } \\
\text { (p. 187) }\end{array}$ & $\begin{array}{l}\text { la mer de Gloria, ni la } \\
\text { montagne des Orgãos, ni } \\
\text { la fortresse de Santa } \\
\text { Cruz et les autres } \\
\text { (p. 307) }\end{array}$ & $\begin{array}{l}\text { sea from the Glória, nor the } \\
\text { Serra dos Órgãos, the Fortress } \\
\text { of Santa Cruz and the others } \\
\text { (p. 227) }\end{array}$ \\
\hline Rio Grande (p. 193) & Rio Grande (p. 317) & $\begin{array}{l}\text { Rio Grande (p. 234) } \\
\text { [acompanhado da nota de } \\
\text { rodapé: "Rio Grande do Sul, } \\
\text { the southernmost province of } \\
\text { the Empire, bordering on } \\
\text { Uruguay."] }\end{array}$ \\
\hline
\end{tabular}


A partir das comparações que aparecem no quadro, pode-se tecer diversas observações. A primeira delas, gritante, é a preservação dos nomes brasileiros na versão inglesa, quase sempre acompanhados de notas de rodapé explicativas, em contraposição às traduções irregulares dos nomes em francês.

As traduções do francês são irregulares porque, embora sempre modificadas na identificação ("rue de", "place de"), nem todos os nomes em si foram traduzidos, embora alguns sim. "Rua das Violas" e "Rua da Quitanda”, por exemplo, seriam também traduzíveis, mas Quint optou por traduzir apenas "Rua dos Inválidos” (por "rue des Invalides") e "Rua da Princesa" (por "rue de la Princesse"). Essa irregularidade prejudica a fluência do texto: nem as personagens se referem a lugares em seus nomes originais, nem a todos em francês. Além disso, "rue des Invalides" e "rue de la Princesse” não existiam no Rio de Janeiro, portanto são invenções. Mas, ainda se todos os nomes de lugares fossem invenções na tradução em francês, seria possível pensar em um caminho lógico adotado pela tradutora. Da forma que está, não se pode compreender as opções adotadas.

Ademais, aqui entra a polêmica questão da tradução de endereços. Como traduzir o nome de um lugar real, que, portanto, precisa ser localizado por seu nome próprio? Imaginando-se que um turista venha ao Rio de Janeiro em posse da tradução francesa, ele teria certo trabalho para encontrar lugares aos quais o narrador de Dom Casmurro se refere - não que seja um propósito do livro servir de guia de turismo, evidentemente. É só um exemplo para ilustrar como a tradução de nomes próprios de locais pode ser problemática, embora haja essa flexibilidade na tradução literária.

A questão da acentuação no francês também chama a atenção. Aqui, porém, imagina-se que a lógica seja a da pronúncia: Quint teria pensado em mimetizar a pronúncia em português para o leitor do francês. Itaguaí tornou-se Itaguaï, Andaraí virou Andaraï, Glória passou para Gloria e assim por diante. No entanto, nota-se um deslize na repetição de Petrópolis, que, na primeira ocorrência, teve seu acento agudo deslocado (Pétropolis), mas depois aparece sem acento, como Petropolis (QUINT, p. 8 e 298).

De modo geral, já com base nesse primeiro quadro de comparação, é possível afirmar que Quint optou, com mais frequência, por levar ao francês o português do que o inverso. A língua portuguesa falada no Brasil da época (e, na maioria das vezes, hoje em dia também) fatalmente aparece no texto, como em Engenho Novo, Flamengo e Corcovado, mas, à medida que ela pôde ser apagada, ela o foi. As traduções dos logradouros podem ser, portanto, consideradas etnocêntricas, pois "engolem” o original.

Sobre esse tipo etnocêntrico de tradução, Antoine Berman escreve:

Etnocêntrico significará aqui: que traz tudo à sua própria cultura, às suas normas e valores, e considera o que se encontra fora dela - o Estrangeiro como negativo ou, no máximo, bom para ser anexado, para aumentar a riqueza desta cultura. (BERMAN, p. 39)

A esse raciocínio, pode-se acrescentar que a tradução etnocêntrica pode simplesmente não considerar importantes detalhes da outra cultura. Nesse sentido, não julga o Estrangeiro negativo, mas sim sem importância e, por isso, o negligencia. Que relevância teria para a leitura do romance, por exemplo, saber o nome verdadeiro da Rua da Princesa, no Rio de Janeiro? Relevância talvez não, mas, em posse do nome 
original, pode-se descobrir que hoje essa é a Rua Paissandu, e que à época o "Princesa" era referência à Princesa Isabel. ${ }^{1}$

Detalhes como esse podem realmente fazer pouca diferença para o texto como um todo, mas não deixa de demonstrar uma veia etnocêntrica e/ou domesticadora, como se apreende de Venuti (2002), no sentido de facilitar a experiência do leitor para que os termos que aparecem no texto não lhe pareçam tão distantes e complicados.

Outro aspecto interessante na versão francesa é que Quint não deixou Minas como no original, na referência a Minas Gerais (QUINT, p. 298), mas Rio Grande sim - ou por não ter entendido a referência ao Rio Grande do Sul (que é mesmo um pouco obscura), ou por, novamente, não se atentar ao padrão adotado da tradução.

Em relação às notas explicativas, apenas uma coincide com uma explicação na versão de John Gledson, a da "fortaleza de Laje”. Entre os lugares apontados no quadro, apenas outro vem acompanhado de nota de rodapé, o "quartel de Barbonos" sobre este, não há comentários na versão em inglês.

As notas aparecem em profusão na versão em inglês. Gledson explica quase todos os lugares relevantes com notas de rodapé. Com elas, entendem-se detalhes que nem sempre são evidentes para o leitor, como o pai de Bentinho como plantador de cana-de-açúcar e a escalada social de Escobar. A opção pelo uso de notas de rodapé ao longo do texto literário é, no entanto, controversa para alguns, que acreditariam que elas prejudicam o processo mimético ${ }^{2}$.

Gledson, no entanto, justifica o seu uso em um ensaio sobre Dom Casmurro:

Tanto a tradução de Helen Caldwell quanto a de Robert Scott-Buccleuch [correção no nome] dispensam notas, como se esse apelo universal conferisse transparência ao romance. O comentário de um colega de Liverpool, que leu Machado por curiosidade e que não é especialista em língua portuguesa, embora leia português, apoia minha opinião de que é necessário dar mais ajuda aos leitores, sem sobrecarregar o texto com demasiadas notas. (GLEDSON, 2006, p. 283).

De toda forma, a riqueza de conteúdo das notas de Gledson é inegável, pois, com elas, a geografia do Rio de Janeiro à época é esmiuçada. Mesmo para leitores brasileiros, elas acabam sendo bastante esclarecedoras e informativas, como a questão da Renânia como herança da imigração alemã estimulada por Dom Pedro II e a função das ruas no antigo centro do Rio de Janeiro, além da hierarquia social dos bairros.

Uma das opções de Gledson, contudo, é curiosa: a tradução de Passeio Público como Promenade. Embora a tradução em si pareça correta (embora houvesse outras opções, como Public Garden, na linha da tradução de Quint), não é claro por que, dessa vez específica, ele optou por traduzir em vez de deixar como no original. Talvez - e esta é só uma especulação - porque Passeio Público apareça no título do capítulo XXV, no original "No Passeio Público" e, em sua tradução, “At the Promenade” (GLEDSON, 1997, p. 47). No entanto, o Passeio Público do Rio de

\footnotetext{
1 Informação da Biblioteca da $\quad$ Fundação $\quad$ Cerierj, <www.educacaopublica.rj.gov.br/biblioteca/historia/0080.html> (acesso em 09-mai-2013).

${ }^{2}$ Em palestra recente realizada na UFSC, em abril de 2013, Clifford E. Landers, tradutor americano de Rubem Fonseca, entre outros autores brasileiros, declarou não usar notas de rodapé, nem concordar com o seu uso frequente em obras literárias.
} 
Janeiro é um lugar específico, portanto esse é um nome próprio - seguindo a padronização proposta em todo o texto, seria de se esperar que Gledson também tivesse deixado no original ou, no máximo, optado por algo mais próximo, que não é o caso de Promenade, um termo peculiar, de origem francesa.

Opção comum aos dois tradutores, a mudança, por exemplo, de S. Paulo e S. Francisco para São Paulo e São Francisco, os nomes completos, será notada também nas dos nomes das personagens - D. Glória, por exemplo, será Dona Glória em inglês e dona Gloria em francês. Essas alterações são compreensíveis, já que realmente representam um desafio tanto para o tradutor quanto para o leitor, além de não gerar diferença de sentido. No caso dos lugares, principalmente, é possível que, se o texto fosse adaptado para o português atual, seus nomes também aparecessem completos.

Outro ponto a reparar em relação aos nomes é a “destradução” de Bordéus, cidade francesa conhecida hoje, mesmo entre brasileiros, por seu nome original: Bordeaux, adotado pelos dois tradutores.

\section{Nomes de personagens e formas de tratamento}

Como é comum em romances, Dom Casmurro possui numerosas personagens, embora a ação seja focada, sobretudo, em Bentinho/Bento, o narrador; D. Glória, José Dias, Tio Cosme e Prima Justina, que moram na casa de Bentinho; Capitu, a vizinha por quem ele se apaixona; e, mais tarde, também Sancha e Escobar, amigos do casal.

Embora poucos nomes próprios tenham sido modificados em francês por Quint (embora, entre eles, os nomes-chave de Dom Casmurro e Capitu) e nenhum por Gledson, as formas de tratamento foram com frequência modificadas nas duas traduções, como se vê no quadro:

\begin{tabular}{|l|l|l|}
\hline \multicolumn{1}{|c|}{ NOME } & \multicolumn{1}{|c|}{$\begin{array}{c}\text { QUINT } \\
\mathbf{1 9 8 3} \text { - edição de 2002 }\end{array}$} & \multicolumn{1}{c|}{$\begin{array}{c}\text { GLEDSON } \\
\mathbf{1 9 9 7}\end{array}$} \\
\hline Dom Casmurro & $\begin{array}{l}\text { Monsieur du Bourru } \\
\text { “...) Dom Casmurro, } \\
\text { autrement dit, Monsieur } \\
\text { du Bourru.” (p. 7) }\end{array}$ & Dom Casmurro \\
\hline $\begin{array}{l}\text { D. Glória } \\
\text { mana Glória } \\
\text { prima Glória }\end{array}$ & $\begin{array}{l}\text { dona Gloria } \\
\text { Gloria, ma soeur } \\
\text { cousine Gloria }\end{array}$ & $\begin{array}{l}\text { Dona Glória } \\
\text { sister Glória } \\
\text { cousin Glória }\end{array}$ \\
\hline $\begin{array}{l}\text { Bentinho } \\
\text { Sr. Bentinho }\end{array}$ & $\begin{array}{l}\text { Bentinho } \\
\text { M. Bentinho }\end{array}$ & $\begin{array}{l}\text { Bentinho } \\
\text { Senhor Bentinho }\end{array}$ \\
\hline José Dias & José Dias & José Dias \\
\hline Pádua & Padua & Pádua \\
\hline $\begin{array}{l}\text { Capitu } \\
\text { D. Capitolina }\end{array}$ & $\begin{array}{l}\text { Capitou } \\
\text { dona Capitolina }\end{array}$ & $\begin{array}{l}\text { Capitu } \\
\text { Dona Capitolina }\end{array}$ \\
\hline $\begin{array}{l}\text { tio Cosme } \\
\text { mano Cosme } \\
\text { doutor [Cosme implícito] } \\
\text { primo Cosme }\end{array}$ & $\begin{array}{l}\text { oncle Cosme } \\
\text { Cosme, mon frère } \\
\text { docteur }\end{array}$ & $\begin{array}{l}\text { uncle Cosme } \\
\text { brother Cosme } \\
\text { cousin Cosme }\end{array}$ \\
\hline $\begin{array}{l}\text { prima Justina } \\
\text { D. Justina }\end{array}$ & $\begin{array}{l}\text { cousine Justina } \\
\text { dona Justina }\end{array}$ & $\begin{array}{l}\text { cousin Cosme } \\
\text { cousin Justina } \\
\text { Dona Justina }\end{array}$ \\
\hline
\end{tabular}




\begin{tabular}{|c|c|c|}
\hline $\begin{array}{l}\text { Pedro de Albuquerque } \\
\text { Santiago }\end{array}$ & $\begin{array}{l}\text { Pedro de Albuquerque } \\
\text { Santiago }\end{array}$ & $\begin{array}{l}\text { Pedro de Albuquerque } \\
\text { Santiago }\end{array}$ \\
\hline $\begin{array}{l}\text { D. Maria da Glória } \\
\text { Fernandes Santiago }\end{array}$ & $\begin{array}{l}\text { Dona Maria da Gloria } \\
\text { Fernandes Santiago }\end{array}$ & $\begin{array}{l}\text { Dona Maria da Glória } \\
\text { Fernandes Santiago }\end{array}$ \\
\hline doutor João da Costa & docteur João da Costa & Dr. João da Costa \\
\hline $\begin{array}{l}\text { BENTO } \\
\text { CAPITOLINA } \\
\text { p. } 38 \\
\end{array}$ & $\begin{array}{l}\text { BENTO } \\
\text { CAPITOLINA } \\
\text { p. } 37\end{array}$ & $\begin{array}{l}\text { BENTO } \\
\text { CAPITOLINA } \\
\text { p. } 28 \\
\end{array}$ \\
\hline D. Fortunata & Dona Fortunata & Dona Fortunata \\
\hline Joãzinho & Joãozinho & Joãozinho \\
\hline padre Cabral & père Cabral & Father Cabral \\
\hline reitor de S. José & directeur de São José & rector of São José \\
\hline Paula & Paula & Paula \\
\hline $\begin{array}{ll}\text { Sancha } & \\
\text { d. Sancha } & \\
\text { sinhazinha Sancha } \\
\text { sinhazinha Gurgel }\end{array}$ & $\begin{array}{l}\text { Sancha } \\
\text { dona Sancha } \\
\mathrm{M}^{\text {lle }} \text { Sancha } \\
\mathrm{M}^{\text {lle }} \text { Gurgel } \\
\end{array}$ & $\begin{array}{l}\text { Sancha } \\
\text { Dona Sancha } \\
\text { Miss Sancha } \\
\text { Miss Gurgel } \\
\end{array}$ \\
\hline Ezequiel de Sousa Escobar & $\begin{array}{l}\text { Ezéchiel de Sousa } \\
\text { Escobar }\end{array}$ & Ezequiel de Sousa Escobar \\
\hline Gurgel & Gurgel & Gurgel \\
\hline Manduca & Mandouca & Manduca \\
\hline Ezequiel & Ezéchiel & Ezequiel \\
\hline
\end{tabular}

Aqui, a comparação parece ficar mais complexa. A começar, a tradução francesa do nome Dom Casmurro causa certa confusão: o título do livro é "Dom Casmurro et les yeux de ressac" (ou "Dom Casmurro e os olhos de ressaca"), mas, logo na primeira página, é proposta uma explicação:

\begin{tabular}{|l|l|}
\hline \multicolumn{1}{|c|}{ ASSIS, 2012, p. 19 } & \multicolumn{1}{c|}{ QUINT, p. 7 } \\
\hline $\begin{array}{l}\text { No dia seguinte entrou a dizer de mim } \\
\text { nomes feios, e acabou alcunhando-me } \\
\text { Dom Casmurro. }\end{array}$ & $\begin{array}{l}\text { Le jour suivant, il se mit à une dénigrer, } \\
\text { me traitant de tous les noms, et finit par } \\
\text { me surnomer Dom Casmurro, autrement } \\
\text { dit, Monsieur du Bourru. }\end{array}$ \\
\hline
\end{tabular}

A decisão domesticadora de Quint, de explicar o nome Dom Casmurro e traduzi-lo, cria uma trajetória peculiar para o seu leitor: na capa, ele vê Dom Casmurro; se decidir lê-lo, em seguida encontrará na primeira página uma possível tradução de casmurro para o francês (bourru); por fim, passará pelo trecho em que o narrador insinua que tentativas de entender o apelido pelo dicionário seriam inúteis:

\begin{tabular}{|l|l|}
\hline \multicolumn{1}{|c|}{ ASSIS, 2012, p. 19 } & \multicolumn{1}{|c|}{ QUINT, p. 8 } \\
\hline $\begin{array}{l}\text { Não consultes dicionários. Casmurro não } \\
\text { está aqui no sentido que eles lhe dão, } \\
\text { mas no que lhe pôs o vulgo de homem } \\
\text { calado e metido consigo. (ASSIS, p. 19). }\end{array}$ & $\begin{array}{l}\text { Bourru n'a pas dans mon cas le sens } \\
\text { qu'ils lui donnent, mais celui, plus } \\
\text { populaire, d’homme taciturne et } \\
\text { renfermé. (p. 8). }\end{array}$ \\
\hline
\end{tabular}


Em sua versão em inglês, Gledson optou por não dar explicação para Dom Casmurro, o que demonstra não só a sua opção mais estrangeirizadora, como, de certa forma, aproxima a experiência de seu leitor à do próprio leitor brasileiro atual, que em geral também não compreende o apelido Dom Casmurro; casmurro, seja lá em qual acepção for, encontra-se em desuso. Em francês, o termo bourru parece ser mais usado, embora também não seja muito usual.

Assim como fez nos nomes de lugares, Quint optou por traduções fonéticas para os nomes das personagens, valorizando, assim, a pronúncia do leitor. Capitu tornou-se Capitou, assegurando uma pronúncia francesa quase idêntica à do brasileiro. Gloria e Padua perderam os acentos. Já Ezequiel, primeiro nome de Escobar e nome do filho de Bento e Capitu, foi, de fato, traduzido, passando a Ezéchiel. Provavelmente, essa tradução foi baseada no fato de haver esse nome em francês: na Bíblia, o profeta Ezequiel é chamado Ézéchiel.

No que diz respeito às formas de tratamento, há algumas alterações curiosas. No capítulo III, o agregado José Dias chama o tio Cosme de “doutor” (p. 23), como forma de respeito (e, nesse caso específico, talvez de falso respeito) comum em algumas regiões do Brasil ainda hoje; não se trata do "doutor" usado para médicos. Tanto que Cosme não é médico, mas sim advogado, como é explicado no capítulo VI. A tradução de Gledson (Dr. Cosme), portanto, pode confundir o leitor, já que não é comum usar “Dr.” para outros profissionais que não clínicos (sobretudo na Inglaterra). Uma alternativa é que o leitor entenda o "Dr.” como irônico.

"Sinhazinha” é um caso à parte e, de fato, de difícil tradução. Diminutivo de sinhá - por sua vez, forma singular de dizer "senhora” - era um termo em geral adotado por escravos negros ou, depois, por empregados domésticos descendentes desses escravos. Trata-se de uma forma particular de tratamento, que remete automaticamente ao servilismo desses escravos ou empregados, que desenvolviam com as "moças de família” uma relação ao mesmo tempo subserviente e familiar. A expressão aparece em um dos diálogos aparentemente mais desafiadores para tradutores estrangeiros:

\begin{tabular}{|c|c|c|}
\hline ASSIS, 2012, p. 4 & QUINT, p. 48 & GLEDSON, p. 37 \\
\hline $\begin{array}{l}\text { Sinhazinha, qué cocada } \\
\text { hoje? } \\
\text { - Não, respondeu Capitu. } \\
\text { - Cocadinha tá boa. }\end{array}$ & $\begin{array}{l}\text { - Tu veux des macarons, } \\
\text { aujourd'hui, petite } \\
\text { demoiselle? } \\
\text { - Non, répondit Capitou. } \\
\text { - C'est bon, la noix de } \\
\text { coco. }\end{array}$ & $\begin{array}{l}\text { "Missy want coconut } \\
\text { today?" } \\
\text { "No," said Capitu. } \\
\text { "Coconut good." }\end{array}$ \\
\hline
\end{tabular}

Nota-se que as traduções são bem diferentes do original e entre si. Cocada, o doce brasileiro, foi perdido nas duas versões - já que usamos macaron para denominar o doce francês, por que não deixar cocada mesmo? - e também o tratamento "Sinhazinha”, embora o "Missy” se aproxime dele.

Gledson procurou transpor o estilo do diálogo do original, adotando o Missy, tradicionalmente usado como título/tratamento por escravos no sul dos Estados Unidos no século XIX - portanto, uma transposição carregada de sentido também no contexto da língua inglesa. No entanto, a ausência do verbo na terceira fala ("Coconut good”) parece não ter sido bem empregada, já que, em Machado, a estrutura da frase é mantida, mesmo que, pelo vocabulário e a versão coloquial do uso verbal, notemos a 
diferença em relação à norma culta. De toda forma, pode-se dizer que houve uma tentativa de manter o diálogo próximo ao de Machado, fiel à letra.

Comenta Berman sobre esse tipo de opção:

Partir do pressuposto que a tradução é a captação do sentido, é separá-lo de sua letra, de seu corpo mortal, de sua casca terrestre. É optar pelo universal e deixar o particular. A fidelidade ao sentido opõe-se - como para o crente e o filósofo - à fidelidade à letra. Sim, a fidelidade ao sentido é obrigatoriamente uma infidelidade à letra. (BERMAN, 2012, p. 45)

$\mathrm{Na}$ maioria das vezes, é possível afirmar que Gledson opta por essa fidelidade à letra, para que o estilo do texto seja preservado.

Que Bentinho é diminutivo e apelido de Bento é uma conclusão à qual os leitores de versões estrangeiras terão de chegar sozinhos. Esse é um ponto importante para a compreensão do personagem-título do romance, apelidado de Dom Casmurro no início - é assim que começa o romance - porém tratado como Bentinho na maior parte das vezes (embora se apresente, uma vez, como Bento, no capítulo XXVII, “O Portão”).

Já “Bento e Capitolina”, a inscrição feita por Capitu com um prego e mantida pelos dois tradutores, oferece para o leitor (seja ele de língua inglesa, francesa ou portuguesa do Brasil) um desafio: concluir que Capitu é apelido de Capitolina. Pode ser que mesmo o leitor brasileiro surpreenda-se, já que nem Capitolina nem Capitu são nomes usuais atualmente; e nem Capitu é considerado um apelido automático de Capitolina. Para os leitores estrangeiros, o desafio é ainda maior, pois "Capitolina" poderia querer dizer qualquer outra coisa. Pelo contexto, porém, é bem provável que se faça a ligação. Pode-se considerar, aliás, que esse tipo de esforço enriquece o texto.

Ao comparar nomes próprios nas traduções de Dom Casmurro de John Gledson e de Anne-Marie Quint, nota-se a grande diferença entre os caminhos adotados por eles em suas respectivas línguas. A tradução de Gledson permite a presença do estrangeiro - na forma de nomes de ruas, lugares e de pessoas - com mais frequência, enquanto a de Quint apresenta um padrão irregular de tradução, optando às vezes pela tradução de nomes de lugares e outras vezes não e, no caso de nomes de personagens, valorizando a fonética também ora sim, ora não.

A começar pela opção de apresentar uma versão francesa para Dom Casmurro (Monsieur du Bourru), Quint mostra a intenção de domesticar o texto para que fique mais compreensível, sem, contudo, exagerar nessa tendência - afinal, boa parte dos nomes próprios são mantidos, um resquício, talvez, das belas infiéis. No caso de Gledson, nota-se o oposto: desde a primeira página, com duas notas de rodapé e o nome Dom Casmurro não explicado, o leitor é convidado a ler não um texto em inglês, mas claramente um romance brasileiro traduzido.

Seguindo o raciocínio proposto por Berman, assim, a tradução de Quint seria mais etnocêntrica, por impor a cultura francesa sobre a brasileira expressa no texto em diversos momentos. Isso poderia ser explicado pela data de sua tradução, em 1983, quando o Brasil ainda era visto, na maioria das vezes, como um país pobre e periférico - portanto, não merecedor de muita atenção às minúcias de sua cultura.. Porém, a edição utilizada neste trabalho é a de 2002, quando essa realidade, tanto em um sentido quanto no outro, já havia se modificado bastante. A tradução de Quint é comumente encontrada em livrarias de Paris, como a Gilbert-Jeune, e de grandes redes brasileiras ainda hoje, no ano de 2013. 
Gledson, como crítico literário experiente - grande conhecedor da obra de Machado de Assis e do Brasil do século XIX - optou naturalmente, em consonância com a sua trajetória, por um caminho mais "estrangeirizador", que permite ao leitor entrever com maior frequência a cultura que está sendo traduzida e compreendê-la melhor por meio de frequentes notas de rodapé. Ele claramente vê Dom Casmurro como um romance enraizado no seu lugar e no seu tempo. Tendo passado temporadas no Brasil desde a década de 1970 e se interessado pela nossa literatura, Gledson deixa os leitores entreverem uma cultura que a ele é familiar e acessível, compondo, assim, um texto mais mesclado e multicultural.

Cynthia Beatrice Costa

cynthia_costa@uol.com.br

Doutoranda - Pós-Graduação em Estudos da Tradução Universidade Federal de Santa Catarina

\section{Referências}

CRUZ, Mariana. "As ruas do centro através dos clássicos”. In: Revista Educação Pública, n.8, 10-mar-2009. Rio de Janieiro: Fundação Ceierj. ISSN: 19846290. Disponível online: <www.educacaopublica.rj.gov.br/ biblioteca/historia/0080.html>. Acesso em 09-mai-2013.

ASSIS, Machado de. Dom Casmurro. São Paulo: Editora Ática, 2012.

ASSIS, Machado de. Dom Casmurro. (tradução de John Gledson). Nova York: Oxford University Press, 1997.

ASSIS, Machado de. Dom Casmurro et les yeux de ressac. (tradução de Anne-Marie Quint). Paris: Éditions Métailies, 2002.

BERMAN, Antoine. A tradução e a letra ou o albergue do longínquo. Florianópolis: PGET/UFSC, 2012.

VENUTI, Laurence. Escândalos da tradução. Bauru: EDUSC, 2002. 